\title{
Proibição do recurso à força e legítima defesa antiterrorista: legado normativo do combate ao estado islâmico (ISIS)
}

\author{
Prohibition of the use of force and self-defense against \\ terrorsim: normative legacy of fighting the islamic state (ISIS)
}

FELIPE AUGUSTO LOPES CARVALHO'

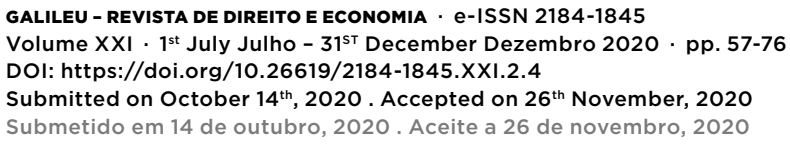

RESUMO: $O$ presente trabalho busca explorar, através de uma pesquisa documental, com ênfase nas Resoluções do Conselho de Segurança da Organização das Nações Unidas, e da análise das discussões doutrinais subjacentes, o estado atual da regulamentação jurídica internacional do recurso à força em ações militares contra o terrorismo, com vistas a refletir se, e em que medida, as ações e ameaças do grupo terrorista Estado Islâmico (ISIS) desencadearam novos contornos à regulamentação da legítima defesa. Conclui-se de maneira afirmativa, no sentido do surgimento de normas que estabelecem que um Estado pode usar a força legalmente, a título de legítima defesa, contra atores não-estatais de cunho terrorista, presentes no território de outro Estado, ainda que independente de seu apoio ou cumplicidade, se este revelar-se incapaz ou relutante em suprimir a ameaça representada por aqueles atores. Os resultados e efeitos dessa mudança no degringolar de novos conflitos restam incertos, o que demandará constante avaliação e exploração pelos estudiosos do tema.

PALAVRAS-CHAVE: Recurso à Força. Legítima Defesa. Terrorismo. Estado Islâmico. Daesh ABSTRACT: This article seeks to explore, through documental research, with an emphasis on United Nations Security Council Resolutions, and by analyzing the underlying doctrinal discussions, the current state of international legal regulation of the use of force in military actions against terrorism, with a view to reflecting on whether, and to what extent, the actions and threats of the Islamic State terrorist group (ISIS) have

1 Doutorando em Direito Público pela Universidade de Coimbra. 
Proibição do recurso à força e legítima defesa antiterrorista: legado normativo do combate ao estado islâmico (ISIS) FELIPE AUGUSTO LOPES CARVALHO

GALILEU - e-ISSN 2184-1845 - Volume XXI - Issue Fascículo 2 - $1^{\text {st }}$ July Julho - 31 $1^{\text {st }}$ December Dezembro 2020 - pp. 57-76

triggered new contours in the regulation of self-defense. It concludes in an affirmative manner, in the sense of the emergence of norms that establish that a State can use the force as a legitimate self-defense against non-state actors of a terrorist nature, present in the territory of another State, although independent of their support or complicity, if they prove unable or unwilling to suppress the threat posed by those actors. The results and effects of this change in the emergence of new conflicts remain uncertain, which will demand constant evaluation and exploration by the researchers on this topic.

KEYWORDS: Use of Force. Self-Defense. Terrorism. Islamic State. Daesh

\section{INTRODUÇÃO}

O direito internacional estabelece uma complexa regulamentação relativa ao recurso à força pelos Estados. A Carta das Nações Unidas fornece a base para esse sistema na atualidade, consolidando a evolução do paradigma da restrição do uso da força, que emerge no século XX, em contraposição ao paradigma anterior, caracterizado pela liberdade e discricionariedade do recurso à força pelos Estados.

Nesse cenário de proibição, o direito de legítima defesa é tratado na Carta como uma das exceções que justificam o uso da força frente à ocorrência de ataques armados, podendo ser considerado um princípio que preserva, mesmo que de maneira limitada, as prerrogativas decorrentes da soberania do Estado de preservar a integridade de seu território, de seus cidadãos e de suas instituições.

O fenômeno do terrorismo internacional, especialmente a partir dos ataques do 11 de setembro nos Estados Unidos, fez emergir novos problemas para o sistema de segurança coletiva estabelecido na Carta. Com efeito, os Estados têm adotado, ao longo das últimas décadas, diversas medidas de repressão e prevenção aos atos de grupos terroristas. No entanto, observa-se que ainda há dificuldades interpretativas da aplicação do direito de legítima defesa em relação a esse fenômeno. Podemos citar, por exemplo, a problemática da caracterização dos ataques perpetrados por grupos terroristas como "ataque armado", nos termos da Carta, e a possibilidade da justificação do recurso à força na chamada legítima defesa preventiva.

O presente trabalho busca explorar, através de uma pesquisa documental, com ênfase nas Resoluções do Conselho de Segurança da Organização das Nações Unidas, e da análise das discussões doutrinais subjacentes, o estado atual da regulamentação jurídica internacional do recurso à força em ações militares contra o terrorismo, com vistas a refletir se e 
em que medida as ações e ameaças do grupo terrorista Estado Islâmico (ISIS) desencadearam novos contornos à regulamentação da legítima defesa.

Em termos de estruturação, a primeira parte do trabalho trata do direito internacional regulamentador do uso da força, inicialmente através de uma breve perspectiva histórica dos documentos que regulam o tema, passando-se à apresentação do arcabouço normativo atual, momento em que será conferida especial atenção às provisões da Carta das Nações Unidas e à atuação do Conselho de Segurança da ONU.

Em seguida, será objeto de estudo a temática da legítima defesa antiterrorista, ou seja, a possibilidade de os Estados utilizarem da força militar como resposta a ataques perpetrados por grupos terroristas. Nessa segunda parte, além de apresentadas as dificuldades conceituais que circundam o terrorismo internacional, serão apreciadas questões fundamentais para uma possível adequação do direito de legítima defesa frente à atuação de grupos terroristas, como os pressupostos e condicionantes do direito de legítima defesa, o conceito e o alcance de ataque armado apto a desencadear o exercício desse direito e os debates que circundam o emprego da chamada legítima defesa antecipatória ou preventiva.

Por fim, o trabalho explorará de que maneira a ascensão do grupo terrorista Estado Islâmico (ISIS), e as reações internacionais por ele desencadeadas, trouxeram novos paradigmas à legitimidade do recurso à força por parte dos Estados, a título de legítima defesa, contra atores não-estatais responsáveis por atos terroristas.

\section{Proibição do Recurso à Força no Direito Internacional: Breve Historiografia}

Até o Século XX, o quadro das relações internacionais se construiu num regime de aceitação do uso da força pelos Estados, considerado um exercício normal da soberania ${ }^{1}$. No século XX, porém, se estabelece a afirmação jurídico-internacional da proscrição do uso da força, em um processo gradual distribuído por quatro momentos, sobre os quais teceremos alguns comentários a seguir: a) A Convenção Drago-Porter e a proibição do uso da força para a cobrança de dívidas; b) O Pacto da Sociedade das Nações e a moratória de guerra; c) O Pacto Briand-Kellog e a renúncia geral ao uso da força; d) A Carta das Nações Unidas e a proibição contundente do uso da força.

1 TORRIJO, Ximena Fuentes - «La prohibición de la amenaza y del uso de la fuerza por el derecho internacional». In: Revista Iberoamericana de Filosofía, Política y Humanidades, v. 16, n. 32, 2014, p. 256. 


\subsection{A Convenção Drago-Porter}

Aos fins do século XIX, num contexto em que comumente os Estados utilizavam a força para cobrar dívidas não pagas de um Estado terceiro no âmbito de uma relação obrigacional, e seguindo-se ao momento histórico onde o Reino Unido, a Alemanha e a Itália usaram da força contra a Venezuela por dívidas não pagas, Luís Drago, à época Ministro dos Negócios Estrangeiros da Argentina, e Horace Porter, o delegado dos Estados Unidos, conseguiram, em meio a intensas negociações diplomáticas envolvendo esses e outros países, extinguir os antigo direito de os Estados poderem cobrar dívidas contra os seus nacionais valendo-se do recurso à força contra os Estados devedores.

A Convenção Drago-Porter, como ficou conhecida, surge no âmbito da $2^{\text {a }}$ Conferência da Haia de 1907, e estabelece, portanto, uma limitação processual ao uso da força, segundo a qual "as partes contratantes não devem utilizar a força armada para a cobrança de dívidas contratuais" ${ }^{2}$. Este foi o primeiro tratado internacional proibindo o uso da força nas relações internacionais, ainda que de forma precária e pontual. Vale considerar, contudo, que a Convenção não negava o uso da força em dois casos: quando o Estado devedor se recusasse a submeter a controvérsia à arbitragem ou se, após aceitá-la, negasse cumpri-la³.

\subsection{Pacto da Sociedade das Nações}

Consumada a I Guerra Mundial, diante dos abusos perpetrados durante o conflito, os Estados uniram-se para celebração do Tratado de Versalhes e do seu corolário, o Pacto da Sociedade das Nações, com o propósito de evitar conflitos bélicos para resolução de futuras disputas entre Estados. Seu texto reflete, sobretudo, uma obrigação mútua assumida pelos membros da Sociedade de respeitar e preservar a integridade territorial e independência política.

O próprio preâmbulo do Pacto expressava que os Estados membros deviam aceitar "certas obrigações de não recorrer à guerra" e desenvolver suas relações internacionais com fundamento na justiça e na honra. Temos aqui o período denominado por Antônio Pereira como a "busca da paz pelo Direito"4.

O marco jurídico internacional trazido pelo Pacto ficaria conhecido por moratória de guerra porque, não sendo uma proibição propriamente dita ao ius ad bellum, impunha o retardamento do uso da força por três meses, com a finalidade de permitir ao Conselho

2 GOUVEIA, Jorge Bacelar - «O Uso da Força no Direito Internacional Público». In: Revista Brasileira de Estudos Políticos, n. 107, 2013, pp. 156 ss.

3 COSTA, Larissa Maria Lima - Arbitragem Internacional e Investimento Estrangeiro. Florianópolis, 2006, p. 57.

4 PEREIRA, Antônio Celso Alves - «A Legítima Defesa no Direito Internacional Contemporâneo». In: Revista Interdisciplinar de Direito, v. 7, n. 1, 2010. p. 3 ss. 
pronunciar-se e fazer com que as partes em conflito chegassem a um acordo, de modo que apenas se este procedimento de solução pacífica não resultasse, seria possível o recurso à guerra. Formou-se, assim, a convicção de que a decisão de iniciativa da guerra, relevante à comunidade internacional no seu conjunto, deveria ser filtrada por uma instância internacional ${ }^{5}$.

\subsection{Pacto Briand-Kellogg}

Um dos marcos mais importantes do período entre guerras em relação a proibição do recurso à força para resolução de litígios entre Estados constitui o Tratado Geral de Renúncia à Guerra, também conhecido como Pacto de Paris ou Pacto Briand-Kellogg, o primeiro de proibição geral do uso da força nas relações internacionais, ao nível substantivo, pondo termo à competência discricionária da guerra.

Celebrado em 1928, prevê nos artigos $1 .^{\circ}$ e $2 .^{\circ}$ a condenação do "recurso à guerra para a solução das controvérsias internacionais", bem como reconhece que "o regulamento ou a solução de todas as controvérsias ou conflitos, de quaisquer natureza ou origem que possam surgir entre elas, jamais deverá ser procurado senão por meios pacíficos".

Desenhado inicialmente como um tratado bilateral entre os EUA e a França ${ }^{6}$, tendo por negociadores o Ministro dos Negócios Estrangeiros Francês Aristide Briand e o Secretário de Estado Norte-Americano Frank Kellog, o instrumento acabou por ser aberto à vinculação de outros Estados, dando origem a um Tratado do qual tornaram-se parte mais de 60 Estados.

Dentro dessa sistemática, leciona Valério Mazzuoli, "com exceção da legítima defesa, que continuaria sendo garantida aos Estados agredidos, qualquer outra forma de agres-

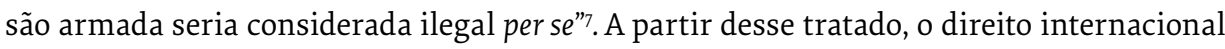
rompe com a ideia de "guerra justa" e passa a condenar explicitamente a guerra enquanto instrumento de política internacional, ao admiti-la somente como medida de ultima ratio, de modo que o uso da força passa a ser considerado permitido apenas como legítima defesa ou como medida de coerção para repelir as mais graves violações do Direito Internacional Público ${ }^{8}$.

5 GOUVEIA, Jorge Bacelar - «O Uso da Força no Direito ...». In: Revista Brasileira de Estudos Políticos, n. 107 , . p. 158.

6 Importante assinalar que, por não terem ratificado o Tratado de Versalhes, os Estados Unidos acabaram não ingressando na Sociedade das Nações. O Pacto Briand-Kellog foi, portanto, negociado e firmado fora do contexto da Sociedade. Para maiores desenvolvimentos sobre o processo de constituição do Pacto, PEREIRA, Antônio Celso Alves - «A Legítima Defesa no Direito ...». In: Revista Interdisciplinar de Direito, v. 7, n. 1, . pp. 4 ss.

7 MAZZUOLI, Valério - Curso de Direito Internacional Público. 9. edição. São Paulo: Malheiros, 2015, p. 1189.

8 PEREIRA, Antônio Celso Alves - «A Legítima Defesa no Direito ... ». In: Revista Interdisciplinar de Direito, v. 7, n. ${ }^{\circ}$ 1, pp. 4 ss. 
Todavia, o Tratado não trazia previsões sobre as consequências da violação desta proibição, bem como não interditava o uso da força em situações que não fossem juridicamente entendidas como guerra.

\section{O Sistema da Carta das Nações Unidas}

\subsection{Princípio da Proibição do Recurso à Força}

A Carta das Nações Unidas estabelece a proibição mais abrangente do uso da força. Nesse sentido, seu Art. 2..$^{\circ}$ n. ${ }^{\circ} 4$ afirma que “Todos os Membros deverão evitar em suas relações internacionais a ameaça ou o uso da força contra a integridade territorial ou a dependência política de qualquer Estado, ou qualquer outra ação incompatível com os Propósitos das Nações Unidas". Esta constitui uma norma imperativa de direito internacional (jus cogens).

Um ponto que merece destaque desde logo é a substituição das referências à "guerra" ou "o recurso à guerra", dando lugar à "ameaça de uso da força”. Isto porque não há um consenso internacional sobre a definição de guerra. Por um lado, há aqueles que enquadram a guerra como uma categoria dentro de conflitos armadas, no qual dois ou mais Estados emitem uma prévia declaração formal de guerra, enquanto outros optam por uma concepção alargada, compreendendo todas as hostilidades armados entre Estados ou entre grupos em um determinado Estado que não tenham um caráter esporádico ou isolado. Assim, o texto da Carta evita as dificuldades técnicas que tinham sido levantadas em documentos anteriores a respeito do significado do termo "guerra".

Com efeito, necessário considerar que a Carta rompe com os paradigmas estabelecidos pela ordem westfaliana, tornando a guerra um ilícito internacional ${ }^{10}$, determinando que, somente nas situações apontadas pela própria Organização das Nações Unidas, os Estados podem recorrer ao uso da força em suas relações internacionais.

9 Jónatas Machado esclarece que se prescinde, para os propósitos da Carta da ONU, a existência de uma declaração de guerra. MACHADO, Jonatas - Direito Internacional. Do Paradigma Clássico ao Pós-11 de Setembro. 4. ${ }^{a}$ edição, 2013 , pp. 397 ss.

10 Para Valéruo Mazzuoli, "a transformação da guerra num ato internacionalmente ilícito deu-se também em virtude da transferência do foro das controvérsias internacionais para as organizações internacionais de vocação universal (cujo exemplo mais marcante é a ONU) ocorrida no século XX, o que acabou por deixar aos Estados a única opção de resolverem suas contendas por meios pacíficos de solução de controvérsias". Cf. MAZZUOLI, Valério - Curso de Direito Internacional ..., p. 1191. 


\subsection{Exceções à proibição do recurso à força}

Apesar da proibição do recurso à força funcionar como regra geral no sistema das Nações Unidas, trata-se de um princípio que comporta exceções, algumas das quais são de aceitação geral, enquanto outras mostram-se controversas.

Uma vez que a Organização das Nações Unidas detém o monopólio do poder bélico público internacional (artigo 24. ${ }^{\circ}, \mathrm{n} .{ }^{\circ}$ da Carta das Nações Unidas), é também a Carta que estabelece as suas exceções, respectivamente no seu capítulo VII e no seu artigo 51. ${ }^{\circ}$. Serão analisadas a seguir as duas exceções literais à proibição do recurso à força previstas na Carta, quais sejam: a autorização do Conselho de segurança e o direito de legítima defesa.

\subsubsection{Autorização do Conselho de Segurança}

O Conselho de Segurança (CS) da ONU é o órgão nuclear da manutenção da paz e segurança internacionais. Dentre as prerrogativas conferidas pela Carta, cita-se o seu poder de ordenar medidas pacíficas para assegurar a paz, a possibilidade de utilizar medidas de coerção econômicas ${ }^{11}$, além da possibilidade de utilizar meios forçosos contra ameaças à paz e seguranças internacionais ${ }^{12}$. Merece destaque, ainda, que as decisões do Conselho têm caráter vinculante ${ }^{13} \mathrm{e}$ as suas Resoluções têm precedência sobre quaisquer outras obrigações internacionais dos Estados ${ }^{14}$.

O capítulo VII é o fundamento para o Conselho de Segurança autorizar operações de manutenção da paz ou intervenções militares. Ao CS cabe declarar o que constitui uma ameaça ou ofensa à paz e à segurança internacionais e ordenar os Estados a cumprirem com as medidas cabíveis. Assim, se o Conselho entender que certa conduta configura uma ameaça ou ofensa, pode autorizar ou ordenar o uso da força em exceção à proibição geral prevista na Carta. Nesses casos, os Estados são os responsáveis imediatos pelas decisões estratégicas relativas à operação militar, mas o CS mantém o poder de controle e comando sobre a generalidade da operação.

Parte da doutrina critica esse poder do Conselho, por revestir-se de um alto grau de discricionariedade na análise dos casos em concreto, além de o CS não precisar se ater a casos de legítima defesa ou de consentimento. Por outro lado, tem sido alvo de críticas também o formalismo rígido que sustenta a necessidade absoluta de uma autorização do CS para o recurso à força, à luz de princípios extremos de necessidade e emergência ${ }^{15}$.

11 Artigo 41..$^{\circ}$ da Carta das Nações Unidas.

12 Artigo $42 .^{\circ}$ da Carta das Nações Unidas.

13 Artigos $25 .^{\circ}$ e $48 .^{\circ}$ da Carta das Nações Unidas.

14 Artigo 103. ${ }^{\circ}$ da Carta das Nações Unidas.

15 Para Jónatas Machado, em casos como esse, podemos verificar um choque entre a legalidade formal e a legitimidade moral, recordando-nos dos ensinamentos de Hugo Grócio, segundo o qual todas as normas 


\subsubsection{Exercício do Direito de Legítima Defesa}

A principal exceção literal à proibição do uso da força no sistema das Nações Unidas é o direito à legítima defesa, que encontra sua regulamentação no artigo 51 da Carta. Este artigo prevê o direito inerente de legítima defesa individual ou coletiva no caso de ocorrer um ataque armado contra um Membro das Nações Unidas, até que o Conselho de Segurança tenha tomado as medidas necessárias para a manutenção da paz e da segurança internacionais.

De acordo com Giancarlo Gómez ${ }^{16}$, a legítima defesa pode ser classificados em três categorias, a saber: a legítima defesa individual, quando o próprio Estado é a vítima direta de um ataque armado; defesa legítima coletiva, ou seja, a possibilidade de que um grupo de Estados exerça harmoniosamente esse direito quando um de seus membros está sujeito a um ataque armado, geralmente exigindo a existência de um tratado internacional pelo qual os Estados Partes acordem com um sistema de ajuda mútua em caso de ataque armado; e, finalmente, a legítima defesa preventiva, segundo a qual poderiam usar a força não só na defesa contra um ataque armado real e já em curso, mas também no caso de um ataque previsível e iminente, mas que ainda não foi desencadeado. Esta última categoria de legítima defesa, tem sido objeto de intensos debates, que serão analisados posteriormente.

Nos termos da Carta, para que possamos afirmar a legitimidade da defesa, esta precisa revestir-se de certas características essenciais, como a (i) provisoriedade, ou seja, até que o CS tome as medidas necessárias; (ii) subsidiariedade, já que o recurso à força defensiva deve ser utilizado apenas como ultima ratio; (iii) dever de notificação de todas as medidas tomadas ao CS; (iv) proporcional à gravidade do ataque impetrado. Para além disso, destacam-se ainda o princípio da legitimidade do meio, adequação e proporcionalidade em sentido estrito na relação meio/fim, sem prejuízo do respeito às demais normas imperativas do direito internacional. ${ }^{17}$

Imperioso destacar que o artigo 51 prevê apenas a hipótese de um "ataque armado" e não a ameaça de um ataque. Ainda assim, o artigo não oferece respostas completas à problemática do conteúdo e escopo da expressão "ataque armado", que desencadeia o recurso à força no seu caráter defensivo, em especial as questões sobre (a) quem poderia cometê-lo, ou seja, somente estados ou também atores não estatais, (b) qual o nível de violência neces-

humanas têm que ser ajustadas de modo a que não sejam vinculativas em caso de necessidade. MACHADO, Jonatas - Direito Internacional..., 4 . $^{\text {a }}$ edição, pp. 475 e ss.

16 GÓMEZ, Giancarlo Mosciatti - Uso de la Fuerza y Terrorismo en el Derecho Internacional. Santiago do Chile, 2010, p. 209.

17 MACHADO, Jonatas - Direito Internacional ..., 4 . $^{\mathrm{a}}$ edição, p. 476. 
sário para considerar que uma ação militar constitui um ataque marcado e (c) a possibilidade de legítima defesa preventiva, ou seja, contra ataques que ainda não ocorreram ${ }^{18}$. A análise dessas três questões é imprescindível para determinarmos se é possível fundamentar, à luz do sistema das Nações Unidas, o recurso à força contra ataques terroristas com base na exceção da legítima defesa.

Em primeiro lugar, a Carta é silente no que se refere a quem pode ter cometido um ataque armado ensejador do direito inerente à legítima defesa. Contudo, o direito internacional moderno aceita que além das forças militares "tradicionais" do Estado, há atores não-estatais, como bandos armados e grupos paramilitares, que também podem cometer ataques para fins de desencadeamento da legítima defesa.

Com efeito, Pereira ${ }^{19}$ apresenta três correntes acerca da responsabilização de um Estado por atos terroristas cometidos por atores não-estatais. Por um lado, há aqueles que defendem a necessidade de um alto grau de envolvimento do Estado para que atores não-estatais sejam considerados responsáveis por um ataque armado. Temos aqui o chamado teste do "controle efetivo", e isso significa que para que haja responsabilização de um Estado por atos de violência militar, o grau de envolvimento entre Estado e atores não-estatais deve ser suficientemente forte para que estes sejam considerados seus "órgãos de fato". Nesse caso, não basta que haja financiamento, fornecimento de armas ou treinamento, mas as próprias ordens para o cometimento dos atos tem que ser dadas pelo Estado em questão. Uma segunda corrente entende que um ataque armado, para os efeitos de justificar o direito de legítima defesa, pode ser cometido por atores não-estatais, desde que estejam sob o "controle geral" de um Estado. Seguindo esse entendimento, seria necessário que as milícias recebessem financiamento, armas e treinamento para fins de responsabilização. Por fim, a terceira vertente defende que se pode agir em legítima defesa contra atores não-estatais, pois estes seriam capazes de cometer um ataque armado independentemente do apoio de um ou múltiplos Estados.

Um elemento que não pode ser deixado de lado nessa discussão é o fato de que no contexto histórico da elaboração da Carta em 1945, o conceito de ataque armado dificilmente poderia ser concebido aparte das forças armadas regulares de um Estado que enfrentavam o exército de um Estado terceiro. Isso significa que os próprios critérios de determinação da existência de um ataque armado, bem como sua classificação, extensão e e intensidade mudaram desde o fim da Segunda Guerra. Nesse sentido, percebe-se que as caracterísiti-

18 RATNER, Steven - «Self Defense Against Terrorists: The Meaning of Armed Attack». In: Public Law and Legal Theory Working Paper Series, 2012.

19 PEREIRA, Luíza Leão Soares - Jus ad Bellum, "Guerra ao Terror" e legítima defesa contra atores não-estatais, Porto Alegre, 2013, pp. 31 ss. 
cas dos ataques terroristas atuais repousam sobretudo na imprevisibilidade do seu início, seu término e intensidade ${ }^{20}$.

Cabe destacar que o Tribunal Internacional de Justiça tem adotado, nos últimos anos, uma posição restritiva quanto à interpretação do conceito de ataque armado. No caso das atividades militares e paramilitares na e contra a Nicarágua, por exemplo (Nicarágua v. Estados Unidos), o Tribunal afirmou que o exercício da legítima defesa se encontra sujeito a que o estado em causa tivesse sido a própria vítima de um ataque armado. Voltaremos à discussão sobre o conceito e alcance de "ataque armado" ao analisarmos o instituto da legítima defesa antiterrorista.

Conforme se verá adiante, as Resoluções emitidas pelo Conselho de Segurança da ONU pós 11 de setembro asseguraram progressivamente a legítima defesa contra ataques cometidos por grupos terroristas, de modo que hoje percebe-se claramente que o sistema das Nações Unidas abarca a possibilidade do emprego da força em legítima defesa contra ataques armados cometidos por grupos não-estatais e que não dependem de nenhum Estado.

\section{O Direito de Legítima Defesa Antiterrorista}

\subsection{Notas conceituais e manifestações do Terrorismo Internacional}

A primeira grande dificuldade que se nos apresenta é a falta de uma definição consensual sobre o terrorismo. Até mesmo a legislação internacional em vigor não fornece uma definição abrangente e exaustiva do que seria o terrorismo internacional. Essa falta de definição deve-se ao fato de que as ideias de "terrorismo" ou "terrorista" apresentam uma tendência de evolução constante e rápida. Além disso, na base destes conceitos residem ideias com forte teor negativo, de conteúdo emocional, associando-os rapidamente com noções de morte, violência e guerra sobre as pessoas acusadas de tais atos ${ }^{21}$.

De forma geral, o terrorismo pode ser compreendido como uma estratégia de violência utilizada para instalar o terror no seio de um segmento da sociedade, de forma a atingir um objetivo de poder, divulgar uma causa ou levar a cabo uma vingança política ${ }^{22}$. O fenômeno do terrorismo é marcadamente, um ato multifacetado, visto que não possui definição exata, expressa-se de variadas formas e atravessa muitas perspectivas de significado, nomeadamente: forma de governo, ato de Estado e atos praticados contra o Estado ${ }^{23}$.

20 RODRIGUEZ, Luis Ignacio Sánchez - Una cara oscura del Derecho Internacional: Legítima defensa y terrorismo internacional, 2012, p. 277.

21 GÓMEZ, Giancarlo Mosciatti - Uso de la Fuerza y Terrorismo ..., p. 212.

22 MACHADO, Jonatas. Direito Internacional ..., 4. ${ }^{\text {a }}$ edição, p. 490.

23 MELO, Milena Barbosa eLUCENA, Elis Formiga - «A Cooperação Internacional como Instrumento de enfrentamento ao Terrorismo: Uma Análise Do Caso Boko Haram». In: Direito internacional. CONPEDI, 2015. 
Callistar Obi compreende o terrorismo como uma dimensão da insegurança ${ }^{24}$. Para o autor, trata-se de um uso premeditado de ameaça ou violência por grupos subnacionais para obter objetivos políticos ou de interesse próprio por meio da intimidação de pessoas, ataque de estados, territórios por bombardeios, sequestros, ataques suicidas, entre outros. Em outras, palavras, significa uma violência premeditada, baseada em motivos políticos, perpetrada contra alvos não combatentes por grupos subnacionais ou agentes clandestinos.

Mais importante que uma definição perfeita e de aplicação universal sobre o terrorismo, é apontar as suas características intrínsecas e essenciais, de modo a determinar se é possível considerar uma ação em concreto como terrorista ou não. Neste sentido, Louise Richardson apud Gómez ${ }^{25}$ fornece sete características essenciais e necessárias quando da qualificação de uma ação como terrorista:

1. O ato terrorista tem uma inspiração notadamente política, que se destina à realização de mudanças ou manutenção do governo.

2. Os atos terroristas envolvem necessariamente o uso ou ameaça de violência.

3. O terrorismo não procura derrotar seu inimigo através de seus atos, mas procura enviar uma mensagem.

4. O ato e a vítima normalmente têm um significado simbólico (exemplo: ataque de 11/og sobre as torres gêmeas).

5. O terrorismo corresponde a atos de grupos subestatais, ou seja, não se refere aos Estados - embora se considere que alguns Estados usam o terrorismo como instrumento nas relações internacionais.

6. As vítimas dos ataques e o público que procuram alcançar os terroristas não são os mesmos, sendo este último, geralmente o governo, embora às vezes pode ser escolhido como representante de um grupo maior.

7. Os atos terroristas são deliberadamente alvos civis. Isto é o que distingue o terrorismo de outras formas de violência política como a guerrilha.

Nessa seara, dois tipos de terrorismo têm sido identificados, o interno e o transnacional. O terrorismo interno envolve as atividades de terroristas em seu país de acolhimento

24 Por seu turno, a insegurança é vista como uma ameaça crônica à vida humana, territórios, estados, crenças religiosas, propriedades e instituições, entre outros. Entre as suas fontes, pode-se destacar: Resposta emocional interna a uma súbita ameaça externa; Situação externa ameaçadora relativamente constante; terna; Ameaça às crenças, especialmente religião. OBI, Callistar - «Challenges of Insecurity and Terrorism in Nigeria: Implication for National Development». In: OIDA International Journal of Sustainable Development, v. 8, n. 2, 2015, pp. 11 ss.

25 GÓMEZ, Giancarlo Mosciatti - Uso de la Fuerza y Terrorismo ..., pp. 214-215. 
e os seus alvos são os seus concidadãos, suas propriedades e as instituições de seu próprio país. Temos como exemplos as atividades dos grupos terrorista Boko Haram na Nigéria, e Tamils no Sri Lanka. Por outro lado, como o próprio nome afirma, o terrorismo transnacional envolve mais de um país, seja em relação às vítimas, metas, instituições e apoiadores, ou implicações. Um bom exemplo de terrorismo transnacional é o ataque dos EUA do 11/9 e a atuação do Estado Islâmico (ISIS).

\subsection{Direito Internacional do Combate ao Terrorismo Pós-11 de setembro}

Os atentados do 11 de setembro de 2001 às torres gêmeas dos Estados Unidos representaram um "divisor de águas" na regulamentação da proibição do recurso à força no Direito Internacional. Nesse sentido, Jónatas Machado considera que o ataque aproximou-se materialmente da noção de "crime de guerra", além de ter resultado numa reavaliação do risco a nível internacional, fazendo com que o combate ao terrorismo tornasse o novo fio de prumo com base no qual toda a realidade internacional passou a ser reavaliada. ${ }^{26}$

A resposta dos Estados Unidos aos ataques foi rápida e ostensiva, através da coordenação e mobilização de recursos políticos e militares para o combate à Al Qaeda. Do mesmo modo foi a reação da comunidade internacional. Em 12 de setembro de 2001, um dia após o atentado, o Conselho de Segurança aprovou a Resolução 1368, que descreveu os ataques como uma ameaça à paz e segurança internacionais, declarando-se o Conselho disposto a tomar todas as medidas necessárias para restabelecê-las, apelando à comunidade internacional que perseguisse não só os terroristas, mas todos os que com eles colaboram, financiam ou acolhem.

Em seguida, foi aprovada a Resolução $1373^{27}$, onde o Conselho permite, de forma expressa, a legítima defesa individual ou coletiva prevista na Carta para combate ao terrorismo, e reafirma a necessidade de combater, por todos os meios, a ameaça representada pelo terrorismo internacional, com vistas ao restabelecimento da paz e segurança das nações. Destaca-se ainda, no âmbito desta Resolução, a criação de um Comitê de Combate ao Terrorismo (CCT), dotado do objetivo de verificar a aplicação das disposições da Resolução pelos Estados ${ }^{28}$.

Antes do 11/9, estava claro para a comunidade internacional que o direito de usar a força em legítima defesa contra ataques terroristas era controverso. Porém, o apoio quase

26 MACHADO, Jonatas - Direito Internacional ...., 4 . $^{\mathrm{a}}$ edição, p. 494.

27 Publicada em 28 de setembro de 2011.

28 Em março de 2004, criou-se o Counter Terrorism Committe Executive Directorate (CTED). O CTED foi criado com a função inicial de revitalizar o trabalho do CCT ao prover aconselhamento especializado, facilitar a assistência técnica relativa a medidas de combate ao terrorismo e promover uma maior cooperação e coordenação entre os diferentes órgãos da ONU e entre as diversas organizações regionais e intergovernamentais. 
universal que os países demonstraram à possibilidade de os EUA exercerem esse direito em resposta aos ataques sofridos, e a mudança ocorrida no quadro jurídico internacional quanto à extensão do direito de legítima defesa leva-nos à reflexão acerca do impacto deste acontecimento na regulação internacional do recurso à força. Para alguns, as mudanças trazidas em decorrência do ataque foram apenas uma continuação do amplo direito à legítima defesa prevista na Carta; para outros, no entanto, trata-se de um novo direito baseado numa reinterpretação do artigo 51; há, ainda, aqueles que consideraram a aceitação como meramente política e, assim sendo, não serviu para criar um direito de legítima defesa alargado ${ }^{29}$.

Importa salientar que para justificar a permissão do instituto de legítima defesa no combate ao terrorismo, o Conselho de Segurança, através dessas Resoluções, concedeu a esses ataques o caráter de "ataque armado". Esta caracterização levanta debates sobre uma questão preliminar pontuada previamente em nosso estudo, qual seja, determinar se os atos de grupos terroristas, muitas vezes atores não-estatais independentes do controle e suporte de um ou mais Estados específicos, constituem um ataque armado e, por conseguinte, podem legitimar o direito de legítima defesa individual ou coletiva nos termos do artigo $51 .^{\circ}$. Esses aspectos serão considerados em detalhes a seguir.

\subsection{Significado e alcance de "ataque armado"}

No âmbito da regulamentação do direito à legítima defesa enquanto exceção à proibição do recurso à força, a Carta das Nações Unidas, e seu Artigo 51 em especial, não deixam claro se o ataque armado precisa ser perpetrado por um estado ou se pode ser estendido a atores não estatais, mesmo quando há pouca ou nenhuma participação de um Estado. Tradicionalmente, o entendimento dos Estados foi no sentido de que o termo "ataque armado" se aplicava apenas a ataques de Estados, embora também se considerava que os Estados por vezes poderiam realizar ataques armados por meio de atores não estatais. Com efeito, pode-se dizer que o Artigo 51 sempre incluiu ataques de grupos terroristas, mas sempre presumindo que esses atos seriam imputáveis aos Estados.

Nesse sentido, a abordagem do Tribunal Internacional de Justiça, no caso Nicarágua vs Estados Unidos (1986), onde a Corte não considerou a atividade militar da Frente Farabundo Martí para a Libertação Nacional (FMLN) como um ataque armado. No entendimento do Tribunal, as ações poderiam ser imputadas apenas aos Estados da Nicarágua ou Estados Unidos.

29 GRAY, Christine - International Law and the Use of Force. 3 . $^{\text {a }}$ edição. Oxford: Oxford University Press 2008, pp. 198 ss. 
Nos últimos anos, porém, pressionados pelo elevado número de ataques terroristas registrados e a necessidade de oferecerem uma resposta urgente a esse fenômeno, a comunidade internacional começou a lidar com a alegação de que os ataques de atores não-estatais poderiam constituir ataques armados, independentemente da atuação de um Estado (ou Estados) em específico. Nesse sentido, vale recordar que as resoluções analisadas anteriormente (1368, de 12 de setembro de 2001, e 1373, de 28 de setembro de 2001) tiveram como objetivo principal responder a um incidente terrorista, conduzido por um ator não-estatal, num momento em que nenhum Estado afirmou que os atos haviam sido realizados por algum Estado.

Atrelado a isso, temos também as constantes referências dos Estados aos denominados ataques da Al Qaeda ou do Talibã ${ }^{30}$, o que nos leva a admitir que foi estabelecida uma interpretação do artigo 51 segundo a qual o termo ataque armado inclui ações de atores não-estatais, sem a necessidade, portanto, de demonstrar a atribuição, ainda que apenas a título de cumplicidade, a um Estado ${ }^{31}$.

\subsection{Legítima Defesa Preventiva}

O direito de legítima defesa, nos contornos observados até aqui, justifica-se, dentre outros pressupostos, perante a ocorrência de um ataque armado. No entanto, dado o potencial destrutivo massivo das investidas militares por grupos terroristas, alguns entendem que existem situações em que a necessidade, por parte de um Estado que se sente ameaçado, de levar a cabo um ataque preventivo, constitui uma justificação aceitável para o recurso à força ${ }^{32}$. Para isso, argumenta-se que há situações, quando por exemplo um Estado tem evidências que um grupo terrorista detém armas químicas capazes de provocarem danos e perdas irreparáveis, em que simplesmente não é razoável esperar uma utilização dessas armas para que, posteriormente, o Estado possa justificar o recurso à força

30 Cf., por exemplo, o discurso do Secretárgio-Geral do NATO à época, Sr. Lord Robertson. Disponível em: http:// www.nato.int/docu/speech/2001/s011002a.htm.

31 Steven Ratner afirma, ainda, que ocorreram diversas outras situações, desde 2001, de reações internacionais às reivindicações de legítima defesa contra atores não estatais, incluindo a Turquia contra os guerrilheiros do PKK operando a partir do Iraque, a Rússia contra os guerrilheiros chechenos operando a partir da Geórgia e Israel contra os guerrilheiros do Hezbollah operando a partir do Líbano. Tudo isso aponta, no mínimo, para um certo grau de aceitação da alegação geral de que a legítima defesa pode ser invocada, em princípio, contra tais atores, independentemente de seus vínculos com outros Estados. RATNER, Steven - «Self Defense Against Terrorists: The Meaning of Armed Attack». In: Public Law and Legal Theory Working Paper Series. University of Michigan Law School, 2012.

32 Por exemplo, em 1981 Israel atacou um reator nuclear iraquiano ainda em fase de construção, invocando a legítima defesa preventiva. Esta ação valeu-lhe uma condenação pelo Conselho de Segurança da Organização das Nações Unidas. 
pelo direito de legítima defesa. Temos diante de nós, portanto, a teoria da legítima defesa preventiva ou antecipatória.

Para aqueles que defendem o uso dessa doutrina na luta contra o terrorismo, a ameaça deve ser iminente, séria e intensa. Isso significa que não é suficiente um Estado alegar a mera posse de armas ou a simples realização de exercícios militares como fundamentos para a legítima defesa. Em outras palavras, o Estado deve buscar evidências aptas a fundamentar a sua atuação militar, de modo a estabelecer um consenso lógico e racional de que realmente enfrenta um perigo iminente e intenso.

Por outro lado, embora amplamente utilizada pela Bush Doctrine, essa concepção não tem sido adotada pelo corpo iuris internacional, e é alvo de inúmeras críticas, de certo modo lógicas e razoáveis, especialmente de que se trata de uma concepção facilmente sujeita a arbitrariedade e manipulação. Na prática, argumentam os críticos, qualquer Estado poderia alegar a existência de uma ameaça futura capaz de legitimar o uso da força. Destaca-se, ainda, a impossibilidade de calcular a proporcionalidade em um ataque preventivo em vista da incerteza do risco que a alegada ameaça representa.

Para que exista um ato terrorista juridicamente relevante para os fins da legítima defesa, é imperativo que no uso da força esteja envolvido, direta ou indiretamente, um ou mais Estados estrangeiros, nos termos do artigo 51 da Carta. Assim, apenas como um exemplo das suas implicações, a polícia, medidas penais e judiciais pelo governo dos Estados Unidos que foram adotadas em solo americano contra o grupo terrorista Al Qaeda não correspondem ao exercício da legítima defesa, em sentido técnico. Para ativar esse mecanismo contra um Estado, é essencial que o Estado em causa esteja provadamente envolvido em atividades terroristas. De fato, grupos ou movimentos terroristas estão sempre, por definiçãa, no território de um Estado, e podem atuar no território desse Estado (terrorismo doméstico) ou de outro (terrorismo internacional). Se um Estado permite que seu território seja usado para atos terroristas contra outro Estado, torna-se cúmplice, e esta é a primeira condição prévia para conceber teoricamente o exercício de legítima defesa.

\section{Novos Paradigmas frente ao Estado Islâmico (ISIS)}

Em meados de 2014, o grupo militante autodenominado Estado Islâmico (ISIS) ${ }^{33}$ rapidamente assumiu mais de trinta por cento do território da Síria e do Iraque. No processo, capturou bilhões de dólares de campos de petróleo e refinarias, ativos bancários e arma-

33 O nome Estado islâmico reflete a meta declarada do grupo de estabelecer um califado islâmico em todo o Mediterrâneo Oriental. Nas terras que controla, o ISIS impôs editos e condições repressivas aos habitantes, semelhante ao antigo regime do Taliban no Afeganistão. O ISIS já decapitou milhares de cristãos, curdos e xiitas, destruiu santuários xiitas e sítios arqueológicos em áreas sob seu domínio na Síria e no Iraque. 
mentos, tornando-se assim uma das maiores ameaças à paz e à segurança no Oriente Médio ${ }^{34}$.

Com o propósito de eliminar o ISIS, a partir de agosto de 2014, os Estados Unidos inciaram uma campanha de bombardeamentos e ataques no Iraque e na Síria, ajudados por outros países ocidentais e árabe. Com efeito, os primeiros ataques aéreos dos EUA contra o ISIS foram em resposta a uma catástrofe humanitária que se desenrolou no norte do Iraque em agosto de 2014. Depois de capturarem as proximidades de Mosul, as forças do ISIS atacaram várias cidades na região de Sinjar, assassinando milhares de homens, mulheres e crianças Yazidis. A pedido do Primeiro-Ministro do Iraque, os Estados Unidos lançaram a operação Inherent Resolve, consistindo de ataques aéreos generalizados contra alvos do ISIS no Iraque em agosto de 2014. Em setembro de 2014, a França e o Reino Unido se juntaram aos Estados Unidos no bombardeio do ISIS no Iraque ${ }^{35}$.

Destaca-se que embora o governo iraquiano tenha consentido em ações militares estrangeiras contra o ISIS no Iraque ${ }^{36}$, o governo sírio não o fez. Pelo contrário, a Síria, com o apoio da Rússia ${ }^{37}$, protestou que os ataques aéreos em seu território constituíam uma violação injustificável do direito internacional. Os Estados Unidos defenderam-se, alegando, inicialmente, que os ataques aéreos contra o ISIS eram justificados por um direito de intervenção humanitária, pelo direito de usar a força no território de Estados falidos, e como exercício do dirieto de legítima defesa coletiva em nome do governo do Iraque ${ }^{38}$. Assim, mesmo sem o consentimento da Síria ou autorização do Conselho de Segurança,

34 Não se pretende, no escopo do presente trabalho, explorar os acontecimentos histórico-políticos e as bases filosófico-religiosas que deram origem ao ISIS. Para esses esclarecimentos, SCHARF, Michael P. - «How the War Against ISIS Changed International Law». In: Case Western Reserve Journal of International Law, n. ${ }^{\circ} 48,2016$; CALDARARO, Niccolo - m «Al-Qaeda, ISIS, Boko Haram and Forms of Rebellion in the 21st Century in the Vacuum of Ottoman Soviet 'Collapse'». In: Journal of Socialomics, v. 5, n. ${ }^{\circ}$ 2, 2016; TAUSCH, Arno -«Estimates on the Global Threat of Islamic State Terrorism in the Face of the 2015 Paris and Copenhagen Attacks». In: Middle East Review of International Affairs, Rubin Center, Research in International Affairs. v. 19, n. ${ }^{\circ} 1,2015$.

35 SCHARF, Michael P. - «How the War Against ISIS Changed International Law». In: Case Western Reserve Journal of International Law. n. ${ }^{\circ} 48,2016$, p. 10.

36 Para maiores desenvolvimentos sobre os argumentos jurídicos sobre intervenção por convite ocorrida no Iraque, Síria e Líbia, vide BANNELIER, Karine - «Military Interventions Against ISIL in Iraq, Syria and Libya and the Legal Basis of Consent». In: Leiden Journal of International Law, v. 29, n. ${ }^{\circ}$ 3, 2016.

37 Vale destacar que a Rússia, com seu poder de veto dentro do Conselho de Segurança, vetou a autorização do CS para uso da força pelos Estados Unidos na Síria.

38 Nesse sentido, a Carta de Samantha J. Power, representante dos Estados Unidos na ONU, ao Secretário-Geral Ban Ki-moon em 23 de setembro de 2014: “(...) o Governo do Iraque solicitou que os Estados Unidos liderassem os esforços internacionais para atacar os locais do ISIS na Síria, com o objetivo de pôr fim aos contínuos ataques ao Iraque, proteger os cidadãos iraquianos e, em última instância, desempenhar a sua tarefa de recuperar o controlo das fronteiras iraquianas. (...) O ISIS e outros grupos terroristas na Síria são uma ameaça não só para o Iraque, mas também para muitos outros países, incluindo os Estados Unidos e nossos parceiros na região." (tradução nossa). Disponivel em: https://www.justsecurity.org/15436/war-powers-resolution-article-51-letters-force-syriaisil-khorasan-group/. Acesso em 19 ago. 2020. 
em 23 de setembro de 2014 os Estados Unidos iniciaram ataques aéreos contra alvos do ISIS na Síria. Mais tarde, a Jordânia e o Canadá, juntaram-se aos ataques ${ }^{39}$.

O Estado Islâmico reagiu aos ataques sofridos, e em 31 de outubro de 2015 bombardeou um jato russo sobre o deserto do Sinai, matando 224 passageiros ${ }^{40}$; em seguida, no dia 13 de novembro de 2015, atacou um concerto de rock e um evento esportivo em Paris, matando 130 pessoas e ferindo centenas de indivíduos.

Em resposta, o Conselho de Segurança da ONU aprovou por unanimidade, no dia 2 de dezembro de 2015, a Resolução 2249, na qual afirmou que o ISIS constitui uma ameaça global e sem precedentes à paz e à segurança internacionais, e urgiu a Comunidade Internacional a adotar todas as medidas necessárias para erradicar o domínio que o ISIS havia estabelecido na Síria. Nesse sentido, essa Resolução acabou por esclarecer e confirmar que o recurso à força em sede de legítima defesa é admissível contra atores não-estatais, nos casos em que o Estado territorial é incapaz ou não deseja suprimir a ameaça perpetrada por esses agentes ${ }^{41}$.

Assistimos, portanto, à criação de um novo paradigma no regime jurídico internacional do recurso à força contra grupos terroristas, ou, conforme as lições de Michael Scharf, o surgimento de um novo "Momento Grociano"42, onde há a rápida formação de uma nova regra do direito costumeiro internacional, nesse caso o reconhecimento de que o Estado pode legalmente usar a força, a título de legítima defesa, contra atores não-estatais de cunho terrorista, presentes no território de outro Estado, ainda que independente de seu apoio ou cumplicidade, se este revelar-se incapaz ou relutante em suprimir a ameaça representada por aqueles atores.

A postura adotada pelo Conselho de Segurança reverberou em alterações normativas em outros domínios, para além da legítima defesa e uso da força, como por exemplo no Direito do Mar. A Resolução n. 2.292/2016, nesse sentido, dá ensejo à realização do direito de visita em alto-mar sobre embarcação suspeita do tráfico de "armas inseguras" sem autorização do Estado de bandeira ${ }^{43}$.

39 SCHARF, Michael P. - «How the War Against ISIS Changed International Law». In: Case Western Reserve Journal of International Law, n. ${ }^{\circ} 48,2016$, p. 12.

40 The Guardian. Egypt plane crash: Russia says jet was bombed in terror attack. 17 de novembro de 2015. Disponível em: https://www.theguardian.com/world/2015/nov/17/egypt-plane-crash-bomb-jet-russia-security-service. Acesso em 10 jun. 2017.

41 Para maiores desenvolvimentos sobre o tema, vide DEEKS, Ashley - «'Unwilling or Unable': Toward an Normative Framework for Extra-Territorial Self-Defense». In: Virginia Journal of International Law, v. 52, n. ${ }^{\circ} 3$, 2012, p. 483 ss.

42 SCHARF, Michael P. - «How the War Against ISIS Changed International Law». Case Western Reserve Journal of International Law, n. ${ }^{\circ} 48,2016$, p. 52.

43 A Resolução suscitou discussões quanto à compatibilidade de seu conteúdo com a Convenção das Nações Unidas sobre o Direito do Mar. Para Ulisses Reis e Tarin Mont'Alverne Alverne, "o Conselho regulou matéria 


\section{Conclusões}

Os ataques terroristas contra o World Trade Center e o Pentágono em 11 de setembro, os ataques subsequentes do ISIS contra o avião russo e à casa de shows em Paris em 2015, e as reações políticas da comunidade internacional a esses ataques levaram ao surgimento de uma nova regra do direito internacional consuetudinário acerca do uso da força contra atores não-estatais, no qual se inclui o ISIS/Daesh. Nesse sentido, a Resolução 2249 do Conselho de Segurança estabeleceu a possibilidade do exercício de legítima defesa contra atores não-estatais, nos casos em que o Estado territorial é incapaz ou irresoluto em suprimir a ameaça perpetrada.

A implicação desta mudança recentemente aceita no regime jurídico internacional da legítima defesa é que qualquer Estado pode, legalmente, usar a força contra atores terroristas não-estatais - questiona-se se essa previsão poderia se estender a outros tipos de grupos paramilitares como rebeldes, piratas, cartéis de drogas, etc. - presentes no território de outro Estado, se este mostrar-se incapaz ou relutante em suprimir a ameaça representada por aqueles agentes.

Não obstante, importa considerar que o direito do recurso à força contra grupos terroristas está sujeito a várias limitações previstas na Carta das Nações Unidas, que impedirão, em tese, a possibilidade de abuso. Nesse sentido, as ações dos grupos terroristas devem equivaler a um ataque armado, nos termos da Carta, para desencadear o direito de legítima defesa; as investidas militares devem ser dirigidas contra os próprios grupos terroristas, e não ao Estado ou à população civil, a menos que se verifique que o Estado exerce um controlo efetivo sobre as forças terroristas; e a ação militar deve cumprir ainda os requisitos da última ratio, necessidade, proporcionalidade, adequação e dever de notificação ao Conselho de Segurança.

Em março de 2019, as Forças curdo-árabes anunciaram a queda do último bastião do ISIS na Síria, representando o fim do califado do Estado Islâmico depois de quase cinco anos de combates no país44. Embora ainda haja, atualmente, ações terroristas do Daesh e de suas "sucursais" 45 , é certo afirmar que combate a este grupo provocou mudanças no quadro normativo global da proibição do recurso à força. Os resultados e efeitos dessa

alheia ao alcance das suas atribuições, ainda que para isso se tenha valido da retórica da manutenção da paz e da segurança internacionais delineada no Capítulo VII da Carta de São Francisco (1945)". REIS, Ulisses Levy Silvério dos e MONT'ALVERNE, Tarin Cristino Frota - «Terrorismo Internacional e Armas de Destruição em Massa: relativizando a liberdade de navegação, a soberania e o direito de visita em alto-mar». In: Seqüência, n. ${ }^{\circ}$ 82, 2019, p. 113ss.

44 EL PAÍS. Forças curdo-árabes anunciam a queda do último bastião do ISIS na Síria. Disponível em: https://brasil. elpais.com/brasil/2019/03/23/internacional/1553329466_793785.html. Acesso em 17 ago. 2020.

45 PÚBLICO. A luta contra o Daesh e as suas sucursais não acabou. Disponível em: https://www.publico.pt/2019/03/23/ mundo/noticia/califado-acabou-luta-daesh-nao-1866578. Acesso em 18 ago. 2020. 
mudança no degringolar de novos conflitos restam incertos, o que demandará constante avaliação e exploração pelos estudiosos do tema.

\section{REFERÊNCIAS}

ALMEIDA, Francisco Ferreira de - Direito Internacional Público. $2^{\mathrm{a}}$ Edição. Coimbra: Coimbra Editora,. 2003. AZIZ, Sahar F. - Rethinking Counterterrorism in the Age of ISIS: Lessons from Sinai, Texas A\&M University School of Law Legal Studies Research Paper, n. ${ }^{\circ}$ 16, 2016.

BLANK, Laurie - «The Extent of Self-Defense Against Terrorist Groups: For How Long and How Far?». In: Israel Yearbook on Human Rights, v. 47, 2017, pp. 265-136.

BROOKS, Rosa - «War Everywhere: Human Rights, National Security, and the Law of Armed Conflict in the Age of Terrorism». In: University of Pennsylvania Law Review, n. ${ }^{\circ}$ 153, 2004, pp. 675-761.

CALDARARO, Niccolo - «Al-Qaeda, ISIS, Boko Haram and Forms of Rebellion in the 21st Century in the Vacuum of Ottoman Soviet 'Collapse'». In: Journal of Socialomics, v. 5, n. ${ }^{\circ}$ 2, 2016.

COSTA, Larissa Maria Lima. Arbitragem Internacional e Investimento Estrangeiro. Dissertação submetida à Universidade Federal de Santa Catarina para a obtenção do título de Mestre em Direito, Florianópolis, 2006.

DEEKS, Ashley - «'Unwilling or Unable': Toward an Normative Framework for Extra-Territorial SelfDefense». In: Virginia Journal of International Law, v. 52, n. ${ }^{\circ}$ 3, 2012, pp. 483-550.

GOODMAN, Ryan e DEREK, Jinks - «International Law, U.S. War Powers, and the Global War on Terrorism». In: Harvard Law Review, v. 118, 2005, pp. 2653-2662.

GRAY, Christine - International Law and the Use of Force. $3 .^{\mathrm{a}}$ edição. Oxford: Oxford University Press, 2008. GÓMEZ, Giancarlo Mosciatti - Uso de la Fuerza y Terrorismo en el Derecho Internacional. Trabalho de conclusão da licenciatura em Ciências Jurídicas e Sociais. Faculdad de Derecho. Universidad de Chile. Santiago, 2010.

GOUVEIA, Jorge Bacelar - «O Uso da Força no Direito Internacional Público». In: Revista Brasileira de Estudos Políticos, n. ${ }^{\circ}$ 107, 2013, pp. 149-200.

KARINE, Bannelier - «Military Interventions Against ISIL in Iraq, Syria and Libya and the Legal Basis of Consent». In: Leiden Journal of International Law, v. 29, n. ${ }^{\circ}$ 3, 2016, pp. 743-775.

MACHADO, Jonatas - Direito Internacional. Do Paradigma Clássico ao Pós-11 de Setembro. $4 .^{a}$ edição. Coimbra: Coimbra Editora, 2013.

MAZZUOLI, Valério - Curso de Direito Internacional Público. 9. ${ }^{\mathrm{a}}$ edição. São Paulo: Malheiros, 2015.

MELO, Milena Barbosa e LUCENA, Elis Formiga - «A Cooperação Internacional como Instrumento de enfrentamento ao Terrorismo: Uma Análise Do Caso Boko Haram». In: Direito internacional. Florianópolis: CONPEDI, 2015.

OBI, Callistar - «Challenges of Insecurity and Terrorism in Nigeria: Implication for National Development». In: OIDA International Journal of Sustainable Development v. 8, n..$^{\circ}$ 2, 2015, pp. 11-18.

PAUST, Jordan - «Use of Armed Force Against Terrorists in Afghanistan, Iraq, and Beyond». In: Cornell International Law Journal, v. 35, n. ${ }^{\circ}$ 3, 2002, pp. 533-557.

PEREIRA, Antônio Celso Alves - «A Legítima Defesa no Direito Internacional Contemporâneo.In: Revista Interdisciplinar de Direito, 2010, pp. 21-35.

PEREIRA, Luíza Leão Soares - Jus ad Bellum, "Guerra ao Terror" e legítima defesa contra atores não-estatais. Trabalho de Conclusão do curso de graduação em Direito pela Universidade Federal do Rio Grande do Sul. Porto Alegre, 2013. 
RATNER, Steven - «Self Defense Against Terrorists: The Meaning of Armed Attack». In: Public Law and Legal Theory Working Paper Series. University of Michigan Law School, 2012.

REIS, Ulisses Levy Silvério dos e MONT'ALVERNE, Tarin Cristino Frota - «Terrorismo Internacional e Armas de Destruição em Massa: relativizando a liberdade de navegação, a soberania e o direito de visita em alto-mar». In: Seqüência, n. 82, 2019, pp. 92-119.

RODRIGUEZ, Luis Ignacio Sánchez - Una cara oscura del Derecho Internacional: Legítima defensa y terrorismo internacional. Cursos de Derecho Internacional y Relaciones Internacionales de Vitoria, 2012.

SCHARF, Michael - «How the War Against ISIS Changed International Law». In: Case Western Reserve Journal of International Law, n. ${ }^{\circ} 48,2016$, pp. 1-54.

TAMS, Christian J. - «The Use of Force against Terrorists». In: European Journal of International Law, v. 20, n. ${ }^{\circ} 2,2009$, p. 359-397.

TAUSCH, Arno - «Estimates on the Global Threat of Islamic State Terrorism in the Face of the 2015 Paris and Copenhagen Attacks». In: Middle East Review of International Affairs, Rubin Center, Research in International Affairs, v. 19, n. ${ }^{\circ} 1,2015$.

TORRIJO, Ximena Fuentes - «La prohibición de la amenaza y del uso de la fuerza por el derecho internacional». In: Revista Iberoamericana de Filosofía, Política y Humanidades, v. 16, n. ${ }^{\circ} 32,2014$, pp. $255-267$. 